\title{
Fronteiras Urbanas: perspectivas para as investigações em etnomatemática
}

\section{Urban Boundaries: perspectives for researches in Ethnomathematics}

\author{
Cristiane Coppe \\ Mônica Mesquita ${ }^{* *}$
}

\begin{abstract}
Resumo
Neste artigo, fruto das nossas vivências enquanto investigadoras junto à comunidade Terras da Costa em Portugal, pretendemos apresentar os olhares investigativos a partir de dois focos distintos: o projeto Fronteiras Urbanas - A dinâmica de encontros culturais na Educação Comunitária/FU (2012-2014) e a Escola do Bairro, inserida tanto no projeto como no atual Movimento Fronteiras Urbanas/MFU (2015). Tal proposta será mediada pelas teorias do Programa Etnomatemática e da Educação Comunitária, proporcionando o trabalho com a Etnografia Crítica, na qual o processo botton-up mobilizou as ações e as investigações na/com a comunidade, enraizando-se no contexto da dialogicidade freireana e do currículo Trivium de D`Ambrosio. Nosso eixo central é o conceito de Fronteira, que nos fez refletir sobre as relações que os caminhos e as perspectivas das investigações em Etnomatemática mantêm com as comunidades envolventes, pois acreditamos que o investigador nessa área encontra-se em constante movimento e que a topologia das fronteiras, estabelecida face a este movimento, pode reconstituir de forma integrativa o papel humanizador e político do investigador na comunidade.
\end{abstract}

Palavras-chave: Programa Etnomatemática. Educação Comunitária. Dialogicidade. Escola Comunitária.

\begin{abstract}
The present article is fruit of our shared experiences as researchers within the community of Terras da Costa, Portugal. Our goal is to present our view as researchers focusing on two different perspectives: the Urban Boundaries project - The dynamics of cultural encounters in community education/UB (2012-2014), and the

\footnotetext{
*Pós-doutorado em Ciências da Educação pela Universidade de Lisboa (IEUL/CNPq), Lisboa, Portugal. Doutorado em Educação pela Universidade de São Paulo (FEUSP), São Paulo/SP. Mestrado em Educação Matemática pela Universidade Estadual Paulista (UNESP), Rio Claro/SP. Coordenadora do GT 5 - História da Matemática e Cultura da Sociedade Brasileira de Educação Matemática (SBEM) e membro do GEPEm - Grupo de Estudos e Pesquisas em Etnomatemática (FEUSP). Docente do curso de Matemática da Faculdade de Ciências Integradas do Pontal (SIGLA), Cidade/UF, e do Programa de Pós-Graduação em Ensino de Ciências e Matemática (PPGECM) da Universidade Federal de Uberlândia (UFU), Uberlândia/MG. Endereço para correspondência: Rua 20, n 1600, Bairro Tupã, Ituiutaba/MG, CEP 38304-402. E-mail: criscopp@ pontal.ufu.br.

***ós-Doutoranda em Ciências da Educação pela Universidade de Lisboa (IEUL), Lisboa, Portugal. Doutorado em Ciências da Educação pela Universidade Nova de Lisboa (UNL/FCT), Lisboa, Portugal. Mestrado em Educação Matemática pela Pontifícia Universidade Católica (PUC/SP), São Paulo/SP. Investigadora Principal do Projeto Fronteiras Urbanas, fomentado pela Fundação para a Ciências e a Tecnologia sob referência PTDC/CPECED/119695/2010. Coordenadora do GEPEm/Pt - Grupo de Estudos e Pesquisas em Etnomatemática de Portugal (IEUL) e membro do GEPEm - Grupo de Estudos e Pesquisas em Etnomatemática (FEUSP). Investigadora do Instituto de Educação da Universidade de Lisboa e docente colaboradora do Mestrado Intercultural (IEUL). Co-leader do TG10 - Diversity and Mathematics Education: Social, cultural and political challenges no CERME - Congress of European Researcher in Mathematics Education. Endereço para correspondência: Qta de Sta Clara, Azinhaga de Pêra, n 134, vivenda D. 2825-17. Caparica / Portugal. E-mail: mbmesquita@ie.ul.pt.
} 
Escola do Bairro (Community School), which was part of the project and remains part of an on-going initiative called Urban Boundaries Movement (2015). This goal is mediated by the theories presented in the Ethnomathematics Programme and in Community Education, which allowed for: (i) working with Critical Ethnography, where research and action with and within the community was a bottom-up process, and (ii) grounding our work in the context of Freire's dialogical process and D'Ambrosio' Curriculum Trivium. The concept of Boundary is our core axis, which lead us to reflect upon the relationship between the pathways and perspectives in Ethnomathematics research and the involved communities. We believe that researchers in this field are in constant movement, and that the topology of boundaries, which is also being constantly established as a result of this movement, can reconstitute the role of politician and humanizer exercised by the researcher inside the community, in an integrative way.

Keywords: Ethnomathematics Program. Communitarian Education. Dialogical Process. Communitarian School.

\section{Introdução}

Acreditamos que todo processo investigativo está em simbiose com a formação do próprio investigador. Nosso encontro de partilhas de experiências, tanto no estágio pósdoutoral, realizado no primeiro semestre de 2015 na Universidade de Lisboa, quanto em decorrência das ações e percepções oriundas do projeto Fronteiras Urbanas (2012-2014), proporcionou-nos, além de novos conhecimentos, o levantamento de ideias e concepções que nos fizeram refletir acerca dos caminhos/trajetórias das investigações na perspectiva da Etnomatemática em/com comunidades. O processo dialógico de formação, estabelecido por meio do desenvolvimento de projetos de pós-doutoramento no Instituto de Educação da Universidade de Lisboa, proporcionou a percepção de linhas teóricas que poderão contribuir para repensarmos caminhos investigativos em Etnomatemática junto a comunidades.

Partindo da mesma perspectiva do encontro, neste artigo pretendemos contextualizar experiências por meio do Programa Etnomatemática e da Educação Comunitária no contexto da dialogicidade freireana e do currículo Trivium de D’Ambrosio (2014), entendendo esse movimento como uma reflexão entre pares que pode se estender aos demais investigadores em Educação Matemática.

Convém ressaltar também que esse exercício de contextualização vem ao encontro do desejo de manifestar, especificamente, os desafios envolvidos na construção de uma educação matemática comunitária nos domínios do projeto Fronteiras Urbanas, pensado para ser e estar na Educação em geral. Neste exercício, torna-se transversal a abordagem de dimensões cruciais que, ao longo das investigações em Educação Matemática, não estão frequentemente endereçadas, tais como: o significado de ser investigador e investigado e o papel do investigador na formação política local da comunidade onde atua. Como as situações concretas de vida dos membros das comunidades foram o cerne das questões de investigação do projeto e estiveram diretamente envolvidas nas relações educativas, os problemas como 
falta de água, falta de oportunidade de inserção na vida ativa local (escola, trabalho, ...), perseguições legais, ausência de condições materiais e crise econômica não puderam ser ignorados ao longo desta investigação, pois tais situações fazem parte da educação matemática.

Em um primeiro momento, apresentaremos nossa visão sobre o Programa Etnomatemática e a Educação Comunitária para, então, partilhar o contexto de nossas experiências no projeto Fronteiras Urbanas que propiciou a reflexão sobre uma Educação Matemática para as relações étnico-raciais.

Abordamos o principal exercício comunitário construído neste projeto e mantido mesmo depois dele - a Escola do Bairro. Deixamos algumas perspectivas em aberto - em forma de convite - para que mais investigadores em Educação Matemática possam contribuir para a reflexão sobre as relações entre fronteiras, sobre os atos investigativos, bem como sobre a forma como estes refletem em nosso encontro com uma comunidade - corpus integrante ou não de nossas investigações.

\section{Programa Etnomatemática e a Educação Comunitária}

Segundo D’Ambrosio (2001), o Programa Etnomatemática é de investigação, mas também possui óbvias implicações pedagógicas, pois amplia seu próprio contexto de estudo, estendendo a Etnomatemática para além da investigação.

As etnomatemáticas, para este autor (2014, p. 10), são estratégias do povo para sobreviver (lidar com o cotidiano) e para transcender (explicar fatos, fenômenos e mistérios e criar opções para o futuro), características da espécie humana, assim, o Programa Etnomatemática é a teorização dessas estratégias. Há inúmeras etnomatemáticas praticadas de formas diferentes por grupos culturalmente identificados (profissionais, trabalhadores, jogadores, crianças brincando, grupos étnicos confraternizando), é uma forma de conhecimento explicado em linguagem comum, sem formalismo próprio, e transmitido por uma pedagogia similar a do ensino mestre-aprendiz, típica do artesanato, em que aquilo que é transmitido é aceito e absorvido, pois funciona na situação específica e satisfaz as pulsões de sobreviver e de transcender. Além do caráter antropológico, a Etnomatemática, de acordo com D’Ambrosio (2001), tem um indiscutível foco político e é embebida de ética, pois prioriza a recuperação da dignidade cultural do ser humano. Nesse sentido, afirma ele que: "a dignidade do indivíduo é violentada pela exclusão social, que se dá muitas vezes por não passar pelas 
barreiras discriminatórias estabelecidas pela sociedade dominante, inclusive e, principalmente, no sistema escolar" (2001, p. 9).

O autor ainda aponta que a Etnomatemática encontra-se em uma dimensão de descolonização para o acesso real dos excluídos e o caminho é restauração da dignidade do ser humano e o reconhecimento de suas raízes culturais. Nessa perspectiva, portanto, ele considera a vertente política como a mais importante da Etnomatemática.

De acordo com Costa e Domingues (2006), a Etnomatemática é o viés da Educação Matemática que reconhece que, tanto nas pesquisas quanto no ensino de Matemática, é possível revelar e valorizar a diversidade, além de evidenciar preconceitos e discriminações, configurando-se, por isso, como uma relevante possibilidade de valorização do Outro no contexto da Educação Matemática.

Em geral, nas práticas educativas nessa disciplina, há a temática cultural, quase sempre ausente da sala de aula e, desse modo, a ciência fica isenta de qualquer relação ou de estabelecer novos discursos para uma educação intercultural. Temas como diversidade, pluralidade cultural, racismo, discriminação, que fazem parte do cotidiano escolar, não são levados em consideração, criando-se um distanciamento entre a relação professor-aluno e a aprendizagem matemática.

Por um lado, é perceptível que a área apresenta dificuldades em contribuir significativamente com a divulgação e a valorização sociocultural da história dos diferentes povos sem privilegiar o olhar exclusivamente eurocêntrico. Como exemplo, podemos citar o fato de que a Matemática origina-se com o povo grego, sendo desconsiderada a oralidade dos povos africanos e babilônicos, ou mesmo que quase nada se produziu em termos de conhecimento matemático, em virtude de não haver registros escritos. A Etnomatemática, nessa perspectiva, é "um caminho para uma educação renovada, capaz de preparar gerações futuras para construir uma civilização mais feliz" (D’AMBROSIO, 2001).

Por outro lado, segundo Domite (2004, p. 420), a opção teórico-metodológica das investigações em Etnomatemática vem construindo um conhecimento fundado na experiência etnográfica, na percepção do "outro grupo", do ângulo de sua lógica, procurando compreendêlo a partir de sua própria racionalidade e termos.

A autora ainda afirma que:

em geral, no âmbito da pesquisa em etnomatemática, o pesquisador/a vive um processo de estranhamento e tensão, visto que as relações quantitativas/espaciais percebidas no grupo investigado - desde que não mais exclusivamente centradas nas explicações do grupo da sociedade do investigador/a - mostram-se muitas vezes, para ele/a, desarticuladas e, em geral, um processo de re-significação e análise das mesmas pede a criação de categorias que envolvem articulações entre a matemática 
e outras áreas do conhecimento como as de história, os mitos, a economia, entre outros. Na verdade, tais relações pedem articulações numa dimensão não disciplinar do conhecimento, mas sim transdisciplinar. (DOMITE, 2004, p. 420)

Com certeza, a Etnomatemática, como potencializadora para se pensar/promover uma Educação Matemática para a diversidade cultural, abre caminhos ao longo da investigação nas/com as comunidades para que isso se efetive. Assim, denominamos a Etnomatemática como potencializadora no sentido de ser uma ferramenta integrativa emancipatória nas dinâmicas dos encontros culturais inseridas nas comunidades-âmago da atual construção social humana. A formação (matemática) comunitária dos que coabitam um mesmo espaço deve proporcionar a emancipação de cada um e ser assentada numa ética de respeito, equidade, alteridade e resiliência.

No projeto Fronteiras Urbanas, a Educação Comunitária é compreendida como aquela desenvolvida nos encontros culturais, cujo objetivo principal é a sobrevivência em uma comunidade e também dela mesma. As bases fundamentais para esta perspetiva educacional assentam-se no conceito de Educação Popular de Paulo Freire, para quem o processo de libertação dá-se por meio do conhecimento local ao conhecimento reconhecido pela sociedade maior - o conhecimento formal. Na Educação Comunitária, a libertação é buscada a partir da valorização do conhecimento local pelas próprias bases - nas comunidades, portanto. A compreensão de que os conhecimentos desenvolvidos nas comunidades são de crucial relevância foi um exercício constante neste projeto.

O conhecimento geracional é, indubitavelmente, um dos sustentáculos da Educação Comunitária, porém são também inquestionáveis os conhecimentos externos que, fruto das relações sociais fora das comunidades, transformam a Educação Comunitária de base, diferenciando-a de comunidade para comunidade, mesmo que tenham características semelhantes.

Na Educação Comunitária, os conhecimentos de cada membro é muito importante para a sustentabilidade de uma determinada comunidade. Assim, o foco do educador dentro dessa perspectiva é fazer com que cada membro reconheça em seu conhecimento uma ferramenta de emancipação que resulte na capacidade de resolução, de escolha e de enfrentamento das problemáticas do dia a dia e, principalmente, compreendam que tais problemáticas advêm do todo da sociedade em que prevalece a hierarquia econômica.

A mais valia de se começar a prestar atenção na educação comunitária das pequenas comunidades é de cunho político emancipatório. Para o sistema neoliberal, do qual somos operantes, é interessante que apenas um conhecimento, o formal, seja reconhecido para que a 
sociedade seja equalizada; caso o ser humano não tenha esse conhecimento reconhecido, é mantido à margem, pois, dentro do aparelho econômico vigente, não há condições para que o mesmo viva, apenas que sobreviva!

No seio de uma comunidade e, mais especificamente nas relações educativas de sobrevivência nela mantidas, é que se presencia a atual emergência para: (1) estar com o outro, (2) com a natureza e (3) repensar a supremacia da espécie humana face às outras formas de vida. Os membros de uma comunidade que são convidados a observar coletivamente os processos educacionais interrelacionais existentes em sua comunidade, a discutir estes processos e a buscar uma análise relacional com a sociedade ao seu redor tornam-se críticos e adquirem um sentimento de pertença, deixando de lado um estranhamento social frequente nos membros das comunidades, além de promoverem uma consciência cívica coletiva. Segundo Barata (2014, p. 174),

\begin{abstract}
a aceitação das ações de educação comunitária e pessoal e do incitamento à criação de uma consciência cívica e reivindicativa são o exemplo perfeito da capacidade de uma coletividade agir a partir do seu interior, ainda que apoiada num conjunto de vontades e valências exteriores e empenhadas.
\end{abstract}

\title{
3 Da investigação: olhares para as Terras da Costa
}

\section{1 ... com lentes do contexto do Movimento Fronteiras Urbanas}

Um grupo de investigadores com diferentes formações acadêmicas, juntamente com alguns membros de duas comunidades locais na Costa de Caparica - Portugal, desenvolveu o projeto Fronteiras Urbanas, um projeto nacional, financiado pela Fundação para a Ciência e a Tecnologia e apoiado pelo Instituto de Educação da Universidade de Lisboa, o qual teve Mônica Mesquita como idealizadora e investigadora principal.

Este projeto acadêmico surgiu como resultado de um longo processo de socialização entre sua pesquisadora principal e duas comunidades locais da Costa de Caparica: Bairro (constituída por moradores de um assentamento ilegal desenvolvido há quatro gerações) e Piscatória (constituída por pescadores locais). Tal socialização teve sua expressão maior num projeto de intervenção no âmbito do Programa Escolhas ${ }^{1}$ : D.A.R. à Costa -Tr@ansFormArte, no qual a coordenadora (pesquisadora principal do projeto acadêmico) e dois educadores voluntários mantiveram um papel ativo crítico.

\footnotetext{
${ }^{1}$ Disponível em: http://www.programaescolhas.pt/
} 
Tal ativismo foi sensível aos conflitos das duas comunidades locais marginalizadas com a sociedade urbana circundante, revelando a clara existência de uma fronteira sócioeconômica. Face a essa sensibilidade, embora o projeto acadêmico em si só tenha começado em 2012, desde 2009 a sua estrutura foi pensada coletivamente por um grupo de pessoas, denominado Movimento Fronteiras Urbanas - oriundas do projeto D.A.R., preocupado com a injustiça e com a falta de dignidade na sobrevivência humana local.

O trabalho diário desenvolvido nas comunidades desde 2009 permitiu aos envolvidos experimentar, discutir e repensar as imagens e ações etnográficas experenciadas, despertando o desejo de construir uma forma mais sistemática de estar juntos, o que foi importante, pois, durante os três anos que precederam o projeto, uma série de obstáculos legais foram encontrados, tornando-se muito difícil estabelecer uma colaboração aberta e emancipatória. Convém ainda ressaltar que o encontro dos membros do Movimento não era benquisto pelas autoridades locais (Câmara Municipal, Igreja e Polícia) que, para deixar claro isso, não hesitaram em destruir um centro cultural construído pelo Movimento Fronteiras Urbanas em 2010, ou constantemente permitir que os membros do grupo sofressem ataques da polícia local.

Costa de Caparica é uma cidade costeira, situada na margem sul do rio Tejo, de frente para Lisboa e, geograficamente, limitada pelo oceano e a face da Arriba Fóssil. É uma cidade dormitório para as pessoas que trabalham na capital e uma importante estância balnear, não só para os turistas de todo o mundo, mas também para a elite de Lisboa que mantém luxuosas propriedades de veraneio e, com isso, garantem o direito de voto no local.

Esta também é uma vila de pescadores, oriunda de duas comunidades distintas de pescadores de Ílhavo e Olhão - localizadas no norte e no sul de Portugal, respectivamente. A comunidade Piscatória está situada na zona costeira desta cidade - conhecida como Costa. Em contraste, a zona rural - localizada na base dos penhascos fósseis, é conhecida como Terras da Costa, região que foi desenvolvida pela comunidade agrícola, sendo atualmente ocupada, embora não em sua totalidade, por populações de imigrantes de outros países majoritariamente de língua portuguesa -, comunidades ciganas e migrantes portugueses, os quais formam a comunidade do Bairro (Terras da Costa).

Tanto uma quanto outra foram silenciadas por uma minoria que se constitui uma maioria política local. Assim, o encontro de ambas com a comunidade acadêmica avivou a proximidade entre elas e as fortificou, alinhando-as em torno de objetivos comuns.

Foi no início de 2010 que membros do Movimento Fronteiras Urbanas iniciaram discussões mais sistemáticas sobre as possibilidades de estarem juntos e, nas inúmeras 
reuniões abertas, cogitou-se a criação de uma associação, uma cooperativa, ou mesmo uma organização não-governamental. No entanto, em virtude de muitos dos membros das duas comunidades locais serem legalmente inelegíveis - ou por serem analfabetos ou por serem ilegais no país - para a criação de qualquer proposta, tais como as previamente mencionadas, seria difícil eles serem aceitos como parte de uma organização mais ampla.

Em algum momento, os membros do Movimento precisaram desenvolver uma maneira legal de estarem juntos e a academia foi uma opção, visto que ali havia um número considerado de investigadores/professores acadêmicos. Assim, segundo o Relatório de Progresso $^{2}$ (2012 - 2013), esta opção foi discutida e aprovada pelos membros das três comunidades que vislumbraram na possibilidade de desenvolver um projeto acadêmico uma maneira de criar um espaço de interação livre e participação comum.

\section{2 ... com lentes do processo do projeto Fronteiras Urbanas}

Nas discussões preliminares à investigação, foi amplamente enfatizado o papel ativo dos membros do Movimento como parte da diversidade cultural representada por eles e da hegemonia urbana em que estavam geograficamente inclusos. Também foram definidos alguns passos para a valorização do conhecimento local, através do processo educativo de ambas as comunidades, processo este centrado na organização e gestão local de situações interativas e diferenciadas de aprendizagem.

Segundo o Relatório de Progresso (2012 - 2013), o principal desenho do projeto Fronteiras Urbanas englobou as estratégias educativas dentro das comunidades multiculturais locais, na intenção de organizar um conjunto de parâmetros que poderiam apoiar um currículo educacional intercultural que fosse baseado na realidade sociocultural e econômica dessas comunidades. Tal currículo, portanto, assentou-se nas práticas educacionais locais geracionais -, as quais mantinham a sobrevivência de ambas as comunidades envolvidas, e nas relações intracomunitárias para constituir o processo do ensino e da aprendizagem de tais práticas. Além disso, considerada a existência de múltiplas culturas dentro de cada comunidade envolvida, cabe ressaltar o viés intercultural desse currículo.

O conhecimento dos desafios educacionais locais permitiu aos membros do Movimento retirar a capa de invisibilidade que pairava sobre os sujeitos de tais comunidades:

\footnotetext{
${ }^{2}$ O Relatório de Progresso é uma das componentes científicas exigidas pelo orgão de fomento Fundação para a Ciência e Tecnologia com o objetivo de delinear, com exaustão, a progressão de um projeto acadêmico. Este relatório dá-se em um ou mais momentos intercalares do projeto, dependendo do seu tempo de duração.
} 
em primeiro lugar, os pescadores impedidos de participar nas decisões públicas locais; depois, os membros da comunidade Bairro que vivem há mais de 40 anos sem água canalizada; e, finalmente, os investigadores envolvidos na luta para criar um espaço no meio acadêmico onde outras vozes pudessem ser ouvidas. A preocupação maior na realização deste projeto foi sempre manter o posicionamento investigativo no âmbito político.

Este processo de co-construção - educação comunitária - garante que as tarefas científicas emerjam das necessidades vividas pelas comunidades locais. Um fator crucial para este facto foi ter membros das comunidades locais a trabalhar no projeto. Como tal, este não foi um projeto top-down, onde um grupo de académicos impõe a sua própria agenda de investigação sobre os membros da comunidade, mas um verdadeiro projeto de bottom-up, onde as vozes das comunidades locais e participantes encontram o outro. Na própria preparação do projeto Fronteiras Urbanas, e como parte do processo contínuo de educação comunitária que ocorreu entre os participantes e as comunidades locais, discutimos o nosso papel como parte da diversidade cultural que representamos e do espaço urbano em que estamos geograficamente incluídos. (MESQUITA, 2014a, p. 25).

O processo de criação do projeto Fronteiras Urbanas nasceu de uma construção coletiva com "o foco de trazer à academia a inovação de se praticar uma investigação onde o tradicionalmente chamado 'objeto de estudo' fosse corpus presente em todo o seu processo." (Mesquita, 2014a, p.26). Ainda na fase de criação, foi idealizado um quadro teórico-dialógico e uma recolha de dados interativa, bem como uma análise de dados crítica, já com a perspectiva de inovar com a construção coletiva destes pontos cruciais em uma investigação acadêmica. Esta proposta de investigação assenta-se no crescente reconhecimento da necessidade de reestruturação da própria prática investigativa educacional.

Sendo assim, ao trazer esta investigação de forma inovadora em suas bases, o objetivo central do projeto Fronteiras Urbanas era:

contribuir, também, para a transformação do sistema acadêmico alimentando-o de humanidade. A academia deve ser também, constituída pelo povo, pelo cidadão local, pela voz das comunidades que circundam os espaços acadêmicos, trazendo, assim, a real possibilidade de desenvolvermos investigações com qualidade, com afetividade e com construções coletivas: investigação COM e não para o cidadão. (MESQUITA, 2014, p. 10).

Para atender à aspiração de trabalhar COM, foi desenhado três movimentos, já citados e abaixo identificados conforme o Relatório de Progresso (2012 - 2013):

(1) Quadro Teórico Dialógico - manter a lucidez teórica face à prática etnográfica que todos os atores sociais desta investigação vivenciariam e face às teorias que encontraríamos na nossa prática. Este ponto, essencial a qualquer investigação acadêmica, funcionou como uma mola em espiral que bebia da teoria em diferentes momentos, de formas mais profundas, em consonância a recolha e a análise de dados. (2) Recolha de Dados Interativa - buscar a participação dos membros das comunidades envolvidas na investigação bem como buscar a participação de novas teorias que trouxessem mais valia ao nosso estar COM estas comunidades. Em constante diálogo com o nosso quadro teórico de base, esta forma da recolha de dados proporcionou a possibilidade de termos uma análise de dados coletiva, aberta e dialógica. (3) Análise de Dados Crítica - perceber, in loco, a concepção, a 
compreensão e a relevância da investigação desenvolvida para todos os atores sociais envolvidos na investigação. Este ponto possibilitou a real construção coletiva e fomentou a consciencialização crítica de todos e COM todos. Uma consciência coletiva foi despertada e o resultado foi a transformação de postura e um novo rumo em direção à emancipação social. (MESQUITA, 2014, p. 11).

\section{3 ... com lentes do foco metodológico no projeto Fronteiras Urbanas}

Em todo o percurso de investigação, foi assumida uma postura etnomatemática ${ }^{3}$ que está liada a um processo de investigação transdisciplinar e transcultural, defendida por Ubiratan D'Ambrósio ao longo de todas as suas obras, cujo pilar é uma práxis integrativa na investigação, a qual suporta uma abordagem bottom-up ${ }^{4}$ e mobiliza as ações ao longo do processo de investigação com os membros das comunidades.

Nesta postura, em que foi extremamente importante olhar para a prática e dialogar com os fenômenos socioeconômicos, com os respectivos contextos e com os membros das comunidades envolvidas, a etnografia crítica acaba não sendo uma escolha metodológica, mas sim a possibilidade de os membros do Movimento serem e estarem investigadores freired'ambrosianos. A busca dos membros do Movimento por um caminho crítico ao comportamento atual na investigação educacional é caracterizada no próprio processo de investigação das populações marginalizadas, porém o foco da investigação deixa de ser um indivíduo ou grupo patológico para ser as minorias, ressaltando a dominação socioeconômica vigente.

Para Thomas (1993), o grande diferencial da etnografia crítica está na aceitação de uma tarefa extra, face a uma situação de desigualdade ou opressão social. Assim, ele assegura:

Critical ethnographers (...) accept an added research task or fraising their voice to speak to an audience on be half of their subjets as a mean so fem powering them by giving more authority to the subjets' voice. As a consequence, critical ethnography proceeds for man explicit framework that, by modifying consciousness or invoking a call to action, at tempts to use knowledge for social change. (THOMAS, 1993, p. 04).

No projeto Fronteiras Urbanas foi acautelado que, de forma geral, os contextos educativos e os conteúdos selecionados para os processos educativos são, majoritariamente, formas de dominação social, pois os contextos, os processos e os conteúdos representam e promovem comportamentos e significações sociais impostos por instituições de poder e, consequentemente, constroem e limitam as escolhas do ser humano. Por este motivo, os membros do Movimento tinham consciência de que o papel do investigador não se limita à

\footnotetext{
${ }^{3}$ Postura Etnomatemática definida por Mesquita, Restivo \& D’Ambrosio (2011).

${ }^{4}$ O termo em inglês significa "de baixo para cima", mas Mesquita (2014a) reinterpreta-o, também, como "de dentro para fora".
} 
mera decodificação de palavras, símbolos e rituais a fim de perceber os significados atribuídos, mas também deve questionar, em conjunto com o corpus investigado, o que poderia ser.

Na concepção de Thomas (1993), a grande questão da etnografia crítica, em que o qualificativo crítica é embasado pela "grounded theory" de Gérin - Lajoie (2009, p.15), é exatamente "o que poderia ser" e, por isso, vai além da "análise puramente descritiva". Tais autores concordam que para apreender as relações de poder e romper com os processos de domesticação é necessária uma abordagem holística, crítica e dialógica das questões investigadas no contexto.

Nessa perspectiva o desafio é olhar os dados sem impor as próprias significações, aceitando os pré-conceitos como construções da própria cultura, de procurar observar, escutar e pensar a realidade estudada a partir de uma visão mais abrangente. Em consonância com Paulo Freire e Ubiratan D’Ambrosio, Thomas (1993) afirma que o investigador deve desenvolver o seu pensamento crítico calcado em uma atitude reflexiva sobre seu trabalho e seus próprios valores, sempre em interação com a comunidade estudada e com as práticas e sinais que ela apresenta.

Embasado por essa percepção, foi construído o projeto Fronteiras Urbanas (20122014), cuja área D’Ambrosio aponta como marcada pela rápida urbanização em virtude dos atrativos turísticos, o que ocasionou dois casos de violações de direitos humanos: a retirada das condições de trabalho de uma comunidade tradicional piscatória e a falta de condições mínimas de sobrevivência digna de cerca de 500 pessoas da comunidade Bairro.

De acordo com o Relatório de Progresso (2012 - 2013), o eixo teórico-metodológico do referido projeto compreende questões da Educação Comunitária (círculos de cultura, arte e educação), do Programa Etnomatemática (currículo Trivium e transculturalidade), da Complexidade Sistêmica (transdisciplinaridade), da Etnografia Crítica (participação ativa crítica do corpus da investigação), bem como da Ética (humanização do espaço). Tal eixo abarca, assim, o próprio exercício vivido nos encontros dos membros do Movimento - as relações intra e interculturais.

O processo de busca e compreensão nas dimensões intra e intercultural foi amplamente desenvolvido e essencial para aclarar os processos educativos intrínsecos às comunidades locais, satisfazendo as necessidades definidas pelos seus membros, em especial a de que houvesse um reconhecimento "simbólico" dessas comunidades pela sociedade como um todo, de que são parte atuante pela diversidade cultural que representam, bem como na hegemonia urbana em que estão inseridas geograficamente. 
O projeto teve como objetivo específico o desenvolvimento de três atividades - a alfabetização crítica, a cartografia múltipla e as histórias de vida - que fossem utilizadas como ferramentas principais para alcançar o objetivo geral. A finalização aconteceu em 2014 com a publicação do livro Fronteiras Urbanas: ensaios sobre a humanização do espaço, que serviu de importante fonte bibliográfica para o encaminhamento de nossas investigações, em nível de pós-doutorado, acerca da possibilidade de pensar a Educação Matemática atrelada às relações étnico-raciais.

Seguindo o percurso da etnografia à etnografia crítica, utilizada no projeto Fronteiras Urbanas, uma das investigadoras (FREIRE, 2014) aponta que, nele, a palavra "crítico" congrega muitas das decisões tomadas em um processo vivido e partilhado pelas três comunidades participantes (comunidades Bairro, Piscatória e Acadêmica). A autora ainda afirma que a linha de ação e de investigação no projeto Fronteiras Urbanas apoiou-se metodologicamente na etnografia crítica, em que são utilizados procedimentos e técnicas da etnografia clássica, contudo, envolvendo os membros das comunidades em processos intencionais de mudança proporcionados pela etnografia a partir da oferta de informação e da visão crítica.

O levantamento de fatos e dados etnográficos no projeto Fronteiras Urbanas e as análises da investigação apoiaram-se tanto na escrita de notas de campo, fotografias e filmes como em documentos com diferentes formas de representação produzidos ao longo do processo. Cabe esclarecer que todas essas ferramentas foram desenvolvidas não só pelos investigadores (membros da comunidade Acadêmica), mas também pelos sujeitos alvos da investigação (membros das comunidades Bairro e Piscatória).

É importante ressaltar que os membros das três comunidades atuaram conjuntamente nas outras, além de alguns deles - como os das comunidades Bairro e Piscatórias participarem de eventos acadêmicos, seja em sessões plenárias, mesas redondas e simpósios, ou escrevendo artigos científicos ou ainda preparando comunicações. Também cabe mencionar a participação coletiva na construção de uma escola voluntária na comunidade Bairro, onde, a pedido dos seus membros, as três comunidades envolvidas trabalharam para a organização de um espaço de aprendizagem local no qual todos pudessem atuar como educando e educador. Essa escola, denominada Escola do Bairro, foi uma atividade coletiva, continuada mesmo após o encerramento do projeto Fronteiras Urbanas, como uma atividade do movimento homônimo. 


\section{4 ...com lentes do continuum: a Escola do Bairro}

Nesta seção, daremos destaque para as atividades vivenciadas junto à Escola do Bairro, espaço oriundo inicialmente do projeto Fronteiras Urbanas e preservado, no primeiro semestre de 2015, a pedido dos seus próprios membros.

Como fruto do trabalho desenvolvido no projeto Fronteiras Urbanas, a Escola do Bairro continuou a existir como um espaço de contexto não-formal sob uma perspectiva de escola comunitária, na qual as figuras do educador e do educando se fundem no processo de aprendizagem e ensino. Tal espaço propiciou, no primeiro semestre de 2015, a organização e a sistematização das reflexões feitas nos encontros por meio do recurso Google docs, tornado um espaço de partilha de ideias e de todo o processo para facilitar o cruzamento de algumas atividades, com flexibilidade para alterações e inserções de novas ideias pensadas e construídas coletivamente.

Os encontros da Escola do Bairro, ocorridos no primeiro semestre de 2015, preservaram as principais atividades oriundas do projeto Fronteiras Urbanas, com o objetivo de:

manter o caminho botton-up do Movimento Fronteiras Urbanas, visando a
autonomia e a civilidade, e do lema do Bunker Roy: "É preciso trabalhar com as
mãos, é preciso ter dignidade de trabalho. É preciso mostrar que se tem uma
habilidade que se pode oferecer à comunidade, prestando um serviço a ela. A ideia é
valorizar o conhecimento local" e integrá-lo não só a esta comunidade, mas à
sociedade com a qual ela interage. Na Escola do Bairro, os professores são
aprendizes e os aprendizes são professores e estes são de anywhere!!!!!! Apenas
somos e juntos. (Relatório de Progresso, 2012-2013).

A organização das atividades da Escola do Bairro, no primeiro semestre de 2015, compreendeu projetos, atividades globais e atividades específicas. Os primeiros são atividades que desenvolvidas pontualmente, porém contínuas (glossário da pesca, o grupo de Batuko...); as seguintes são momentos de encontros previamente organizados, mas que se realizam pontualmente (festas, visitas guiadas,etc.) e, por fim, as últimas, ou específicas, são periódicas e focam-se em temas solicitados pelos membros das três comunidades, seja por necessidade ou desejo (Alfabetização Crítica, Malta do Poema, Grupo de Teatro, Alfabetização Matemática, Permacultura, Momentos da Filosofia Política ...). Essa proposta de criar um documento coletivo tornou as atividades da Escola do Bairro mais dinâmicas, pois propiciou a participação e a interferência de todos com sugestões, coordenações e notas em cada atividade desenvolvida.

Ir às Terras da Costa - Escola do Bairro - era uma atividade dos nossos projetos de pós-doutorado, no entanto, isso era muito mais a exposição das necessidades, implicações e 
desabafos do grupo que uma simples atividade investigativa. Muitos laços se firmaram e, como uma forma de avaliação, os membros do projeto Fronteiras Urbanas trouxeram uma mandala com impressões e perspectivas acerca da sua atual situação: de complexidade sistêmica e das relações que tecem sua condição de SER humano.

Mesmo com um olhar de investigação, de sensibilidade e de solidariedade, o que nos une é o SER (verbo e substantivo), conforme pontua D’Ambrosio (2001). SER humano (substantivo), porque nos importamos com o outro, como D. Vivi que nunca tinha ido à escola e nem à praia, mesmo morando na Costa de Caparica há mais de 35 anos; como o Daniel que, como os outros, busca representar sua identidade individual e coletiva na sociedade: como Rita e da Iliana, duas pessoas muito tímidas; bem como o senhor Guilherme que, sabiamente, busca em família a poesia do discurso do SER. E SER humano (verbo), porque a dinâmica do encontro cultural nos aproxima de onde queremos chegar, de onde o nosso olhar não pode alcançar!

Em nossas saídas externas, no âmbito dos projetos, as buscas esperançosas se efetivam por meio da educação informal, cultural e política das Terras da Costa e, com esse exercício de conhecer nosso entorno social, promove-se o entendimento da nossa condição cultural e econômica. A transformação na própria Educação Comunitária local torna-se visível.

A prática da Escola do Bairro, enquanto ato coletivo, permitiu o exercício de reflexão de nossa própria prática, concepção para além da educação escolar - uma experimentação da prática libertária.

\section{Perspectivas em aberto...}

Percebemos que ao longo do processo de investigação, a perspectiva de uma aprendizagem libertária ${ }^{5}$, de uma prática centrada no educando e não no educador, permeou e permeia as atividades da Escola do Bairro. Na verdade, tal aprendizagem está presente na própria postura etnomatemática dos envolvidos nessa escola e pode ser percebida por meio dos processos de aprendizagem nas práticas de todo o corpus. Dessa forma, a aprendizagem é democratizada, afinal compreendemos que, tanto o educador como o educando, são sujeitos desses processos.

\footnotetext{
${ }^{5} \mathrm{O}$ termo aprendizagem libertária surge de uma reflexão do processo relacional entre a perspectiva da Educação Popular, de Paulo Freire (1970), com os pensamentos educacionais emergentes construídos por Bunkey Roy na Universidade Pés Descalços - Learning from a Barefoot Movement (2011).
} 
A dialogicidade de Paulo Freire é explícita em depoimentos não somente de educadores que atuaram nos encontros de alfabetização matemática. Outra perspectiva encontrada foi o respeito e o conhecimento de todos pela proposta do currículo Trivium que, segundo D’Ambrosio (2014), consolida-se no projeto Fronteiras Urbanas por meio da Literacia, capacidade do corpus de processar criticamente a informação escrita e a falada, de manifestar a leitura, a escrita, o cálculo e o diálogo de forma crítica integrativa; da Materacia, capacidade que ele tem de interpretar e analisar criticamente códigos expostos nas leis opressivas locais e de utilizar modelos e simulações na vida cotidiana; e, por fim, da Tecnoracia, capacidade de usar e combinar criticamente instrumentos, simples ou complexos, inclusive o próprio corpo, avaliando criticamente suas possibilidades, seus desejos e suas limitações e adequando-os às necessidades e situações vividas no cotidiano. A proposta do currículo Trivium ganha corpo nas ações da Escola do Bairro em inúmeras situações como, por exemplo, a partir do cotidiano das mulheres cabo-verdianas, nas relações estabelecidas com o tempo e com o espaço, na gerência para obterem água, na dificuldade de ter que registrar oralmente suas ideias, assim como nas suas necessidades de sobrevivência e transcendência.

Obviamente, as atividades da Escola do Bairro, além de propiciarem a formação da cidadania, da leitura de mundo pelas letras e pelos números - ou pela arte, como diria a Dona Vivi - e outros aspectos concernentes ao que é reconhecido como educação básica, podem também ser um foreground ${ }^{6}$ para alguns moradores dessa comunidade, no sentido de proporcionar a eles a vivência de outros contextos e conhecerem novos olhares sobre o mundo. Tal experiência nos mostrou que a função educacional, em contextos formais ou informais de aprendizagem-ensino, é ultrapassar as fronteiras em busca de novos aportes culturais.

Por um lado, é visível que as investigações que envolvem comunidades tendem a ficar cada vez mais escassas em virtude de algumas dificuldades, dentre elas o tempo de envolvimento e imersão dos investigadores com o grupo, com sua visão de mundo e com a sua própria qualidade identitária. Por outro, a Etnografia Crítica e a Educação Comunitária com currículo Trivium na perspectiva do Programa Etnomatemática podem entrar na pauta das investigações qualitativas em Educação Matemática, como alternativas construtivas

\footnotetext{
${ }^{6}$ Este termo é trabalhado segundo a definição de Ole Skovsmose em um artigo desenvolvido com Helle Alro e Paola Valero, em 2007, e refere-se à interpretação de uma pessoa sobre a relação da aprendizagem com as oportunidades de vida, relação essa em que, para o autor, o contexto sócio-político parece ser central.
} 
na/para a visão/interpretação de mundo dos educandos e dos educadores em situações formais ou informais de ensino.

Enfim, o constante movimento da topologia das fronteiras faz emergir relações entre o investigador e a comunidade, fato possível somente quando o investigador experiência e valora o estar nas fronteiras, âmbito onde o exercício de ser e estar faz emergir relações, não somente decorrentes dos objetivos e metas de um projeto como o Fronteiras Urbanas, mas da aproximação (tanto do investigador como dos membros da comunidade) das tensões de sobrevivência e de transcendência dessa comunidade.

\section{Referências}

BARATA, J. P. Em torno do conceito de espaço urbano. In: MESQUITA, M. (Org.). Fronteiras Urbanas: ensaios sobre a humanização do espaço. Viseu: Anonymage, 2014, p 88-100.

D’AMBROSIO, U. Etnomatemática: elo entre as tradições e a modernidade. Belo Horizonte: Autêntica, 2001.

À guisa de prefácio. In: MESQUITA, M. (Org.). Fronteiras Urbanas: ensaios sobre a humanização do espaço. Viseu: Anonymage, 2014, p 7-18.

COSTA, W. N. G.; DOMINGUES, K. C. M. Educação Matemática, Multiculturalismo e Preconceitos: que homem é tomado como medida de todos os outros? In: Bolema, Rio Claro, v.19, n 25, p. 45-69, maio. 2006.

DOMITE, M. C. S. Da compreensão sobre formação de professores e professoras numa perspectiva etnomatemática. In: KNIJNIK, G.; WANDERER, F.; OLIVEIRA, C. J. (Org.) Etnomatemática: currículo e formação de professores. Santa Cruz do Sul: EDUNISC, 2004, p 419-431.

FREIRE, I. Da Etnografia à Etnografia Crítica. In: MESQUITA, M. (Org.). Fronteiras Urbanas: ensaios sobre a humanização do espaço. Viseu: Anonymage, 2014, p. 81-87.

FREIRE, P. Pedagogia do oprimido. Rio de Janeiro: Paz e Terra, 1970.

GÉRIN-LAJOIE, D. A aplicação da Etnografia Crítica nas Relações de Poder. Revista Lusófona de Educação, Lisboa, v. 14, n 14, p. 13-27, 2009.

MESQUITA, M.; RESTIVO, S.; D’AMBROSIO, U. Asphalt Children and City Streets - A Life, a City, and a Case Study of History, Culture, and Ethnomathematics in São Paulo. Rotterdam: Sense Publishers, 2011.

MESQUITA, M. Fronteiras Urbanas: a dinâmica de encontros culturais na educação comunitária. Relatório de Progresso 2012-2013. Lisboa: Fundação para a Ciência e a Tecnologia, 2014.

MESQUITA, M. Fronteiras Urbanas. Sobre a humanização do espaço. In: MESQUITA, M. (Org.). Fronteiras Urbanas: ensaios sobre a humanização do espaço. Viseu: Anonymage, 2014a, p 19-32.

ROY, B. Learning from a Barefoot Movement. [Ficheiro em Vídeo], 2011. 
SKOVSMOSE, O.; ALRO, H.; VALERO, P. Before you divide, you have to add. Interviewing Indian students' foregrounds. The Montana Mathematics Enthusiast, Missoula, Monograph 1, p.151168, Junho, 2007.

THOMAS, J. Doing Critical Ethnografy. Califórnia: Sage Pub. Co, 1993.

Submetido em Abril de 2015. Aprovado em Agosto de 2015. 